\title{
Evaporation of high speed sporadic meteors
}

\author{
E. Murad ${ }^{1}$ and C. Roth $^{2}$ \\ ${ }^{1}$ Air Force Research Laboratory, Space Vehicles Directorate, Hanscom AFB, MA 01731, USA \\ ${ }^{2}$ Radex, Inc., 3 Preston Court, Bedford, MA 01730, USA
}

Received: 22 September 2003 - Published in Atmos. Chem. Phys. Discuss.: 18 December 2003

Revised: 23 April 2004 - Accepted: 23 April 2004 - Published: 18 May 2004

\begin{abstract}
Recent measurements conducted at the Arecibo Observatory report high-speed sporadic meteors having velocities near $50 \mathrm{~km} / \mathrm{s}$. The results seem to indicate a bimodal velocity distribution in the sporadic meteors (maxima at $\sim 20 \mathrm{~km} / \mathrm{s}$ and $\sim 50 \mathrm{~km} / \mathrm{s}$ ). The particles have a maximum mass of $\sim 1 \mu \mathrm{g}$. This paper will present an analysis of the ablation of $1 \mu \mathrm{g}$ meteoroids having velocities of $20,30,50$, and $70 \mathrm{~km} / \mathrm{s}$. The calculations show that there is fractionation even for the fast meteoroids, the effect being particularly noticeable for the $1 \mu \mathrm{g}$ sporadic particles, and less so for the heavier particles. The relevance of the calculations to the radar observations of the sporadic meteors will be discussed.
\end{abstract}

\section{Introduction}

Sporadic meteors studied using the Arecibo Observatory have indicated the presence of a component that consists of very fast $(\geq 50 \mathrm{~km} / \mathrm{s})$, very light $(1 \mu \mathrm{g})$ meteoroids (Janches et al., 2000, 2001; Mathews et al., 2001, 1997). These observations were confirmed in a subsequent study, also conducted at the Arecibo Observatory (Janches et al., 2002). The ablation of meteoroids has been treated in detail by a number of authors (Flynn, 1989; Hawkes and Jones, 1975; Love and Brownlee, 1991, 1994; Öpik, 1958; Whipple, 1943). We will discuss in this paper the ablation of meteoroids of the mass and velocity that have been observed at Arecibo within the framework of differential ablation (McNeil et al., 1998, 2002).

Before proceeding to the analysis and discussion of the results, it is worth outlining the basis for differential ablation. Analysis of the vaporization process of meteoroids (Jones and Kaiser, 1966) has indicated that consideration of thermal conductivity in the heating meteoroids is not nec-

Correspondence to: E. Murad

(ed.murad@hanscom.af.mil) essary for meteoroids of radius $<1 \mathrm{~mm}$; in other words for such meteoroids the temperature is uniform, and, presumably, a thermal equilibrium is established. The establishment of a thermally-equilibrated meteoroid is the basic assumption behind differential ablation, even though the transit time through the atmosphere is very short. The evaporation and the consequent abundance of the elements would then be according to their thermodynamic properties. The alternative to thermal equilibration is that the meteoroid undergoes pulse heating and all components are deposited as vapor irrespective of the thermal properties. Qualitatively, the difference between the two models can be summarized as follows: thermal equilibration would lead to evaporation of low boiling point metals when the meteoroid temperature reaches $900 \mathrm{~K}$ ( $\mathrm{Na}$ and $\mathrm{K}$ ), while in the case of non-equilibrated or pulseheated meteoroids, evaporation would occur when the temperature of the meteoroid reaches some average temperature, perhaps $1800-2000 \mathrm{~K}$. The consequences of these models are that the thermal equilibrium model would lead to beginning heights that are higher than the pulse-heated model, and that the composition of metal vapor layer in the upper atmosphere (whether ionic or neutral) would show altitude profiles that are different for each for the metals.

Composition data obtained with rocket-borne mass spectrometers (see the review in Grebowsky and Aikin, 2002) seem to support the idea of differential ablation, namely that the different atomic ions have their peak intensities at different altitudes. Moreover, lidar measurements of meteor trails give results that are readily interpretable within the framework of differential ablation (von Zahn et al., 2002).

\subsection{Analysis and discussion}

The processes that are included in the differential ablation (equilibrium) model for meteoroids entering the Earth's atmosphere have been published elsewhere (McNeil et al., 2002). The thermodynamic properties were taken either 


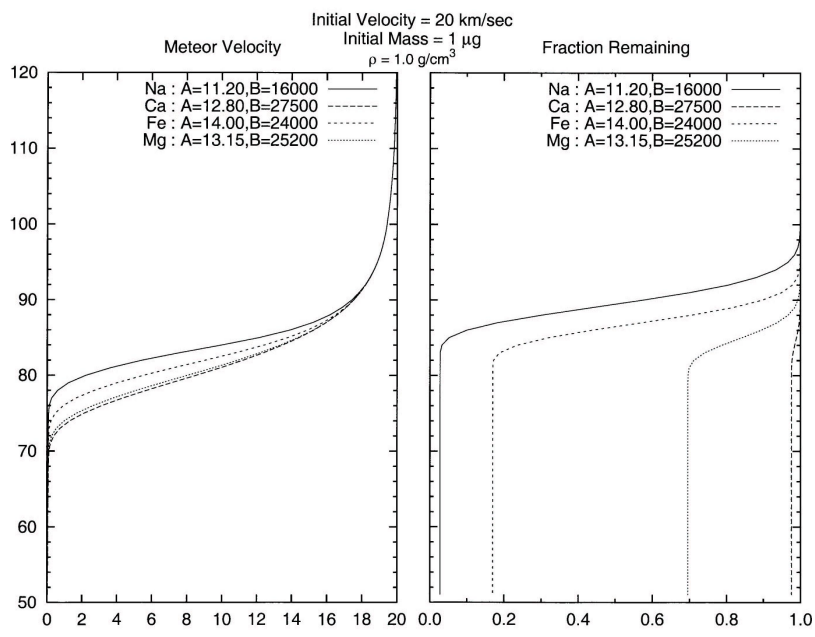

Fig. 1. The ablation of a $1 \mu \mathrm{g}$ particle entering the atmosphere at $20 \mathrm{~km} / \mathrm{s}$.

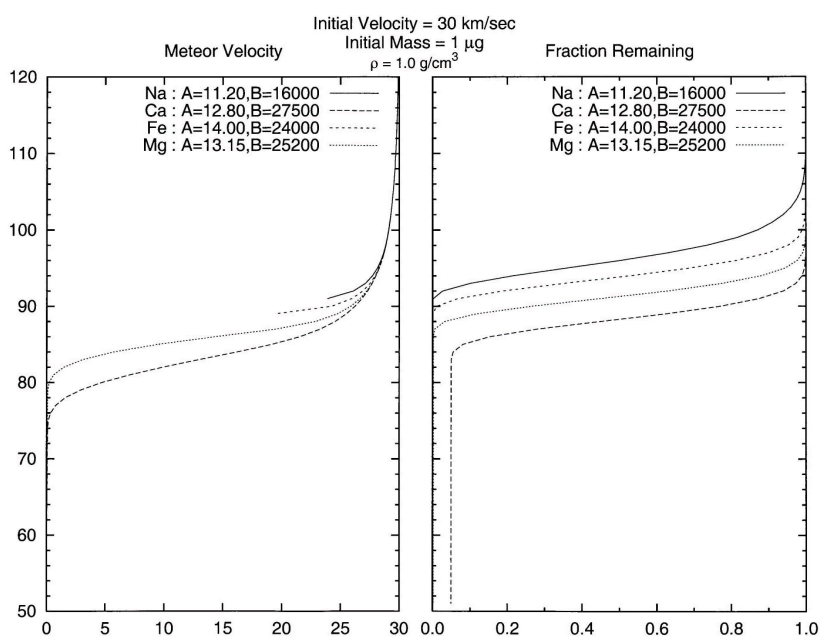

Fig. 2. The ablation of a $1 \mu \mathrm{g}$ particle entering the atmosphere at $30 \mathrm{~km} / \mathrm{s}$.

from the "JANNAF" Tables (Chase, 1998) or were calculated from the "MAGMA" model (Fegley and Cameron, 1987). Our model is similar to the Pure Component Reference (PCR) recently described (Alexander, 2001). The pressure of a component is described by an equation of the form $\ln P_{e q}=A-B / T$. In Figs. 1-4 we show the ablation of a meteoroid of $1 \mu \mathrm{g}$ mass entering the atmosphere at velocities of 20, 30, 50, and $70 \mathrm{~km} / \mathrm{s}$. Assuming a density of $\sim 1 \mathrm{~g} / \mathrm{cm}^{3}$ such a meteoroid corresponds to a radius of $\sim 6 \mu \mathrm{m}$, well below the radius at which thermal conductivity has to be included in the calculation of ablation properties of meteoroids (Jones and Kaiser, 1966). What is clear from the figures is that the evaporation begins at higher altitudes, that the ablation is complete for all these elements. It is worth noting that fractionation is more pronounced for meteoroids of the size

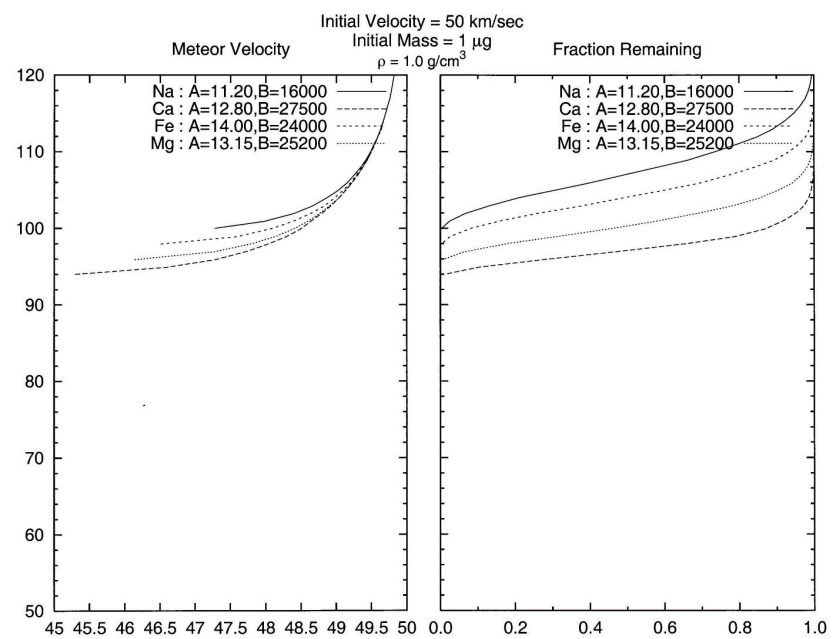

Fig. 3. The ablation of a $1 \mu \mathrm{g}$ particle entering the atmosphere at $50 \mathrm{~km} / \mathrm{s}$.

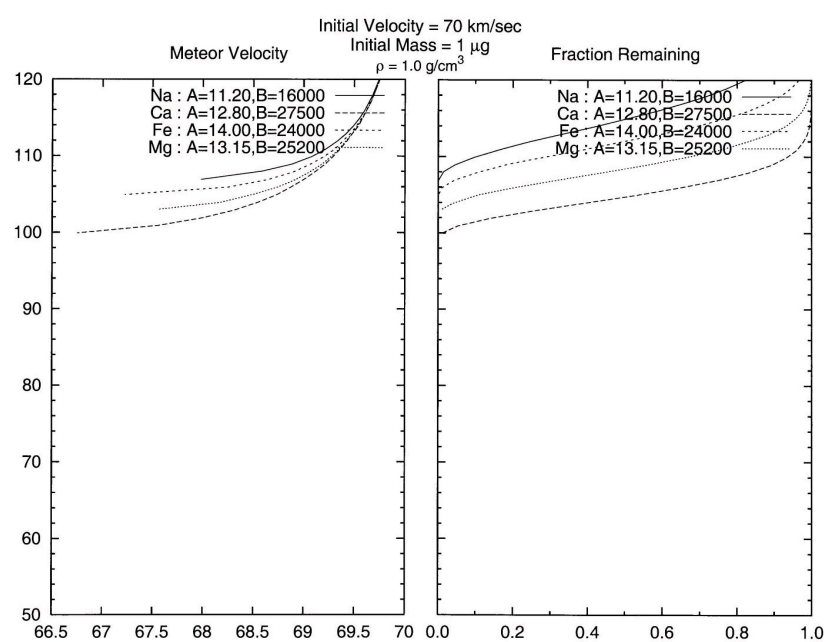

Fig. 4. The ablation of a $1 \mu \mathrm{g}$ particle entering the atmosphere at $70 \mathrm{~km} / \mathrm{s}$.

discussed here $(1 \mu \mathrm{g})$ than for the larger ones, as is shown in Fig. 5 for the ablation of a $10 \mu \mathrm{g}$ meteoroid. The calculations indicate that as the meteoroid velocity increases, its loss of the metals increases; for the $1 \mu \mathrm{g}$ meteoroid most of the Ca survives transit through the atmosphere at $20 \mathrm{~km} / \mathrm{s}$. Even for $\mathrm{Ca}$, the most refractory of the metal oxides, ablation is nearly complete at velocities $\geq 50 \mathrm{~km} / \mathrm{s}$. Also worth mentioning is that the density is an important parameter in modeling the ablation of meteoroids. For a given size and velocity, an increase in density leads to a higher temperature being reached at a given altitude.

At $50 \mathrm{~km} / \mathrm{s}$ deposition of the metals begins at altitudes $\geq 120 \mathrm{~km}$. Since the ablating atoms collide with the atmospheric constituents at the initial meteoroid velocity $(50 \mathrm{~km} / \mathrm{s})$, the net center-of-mass collision energy with $\mathrm{O}$ is 


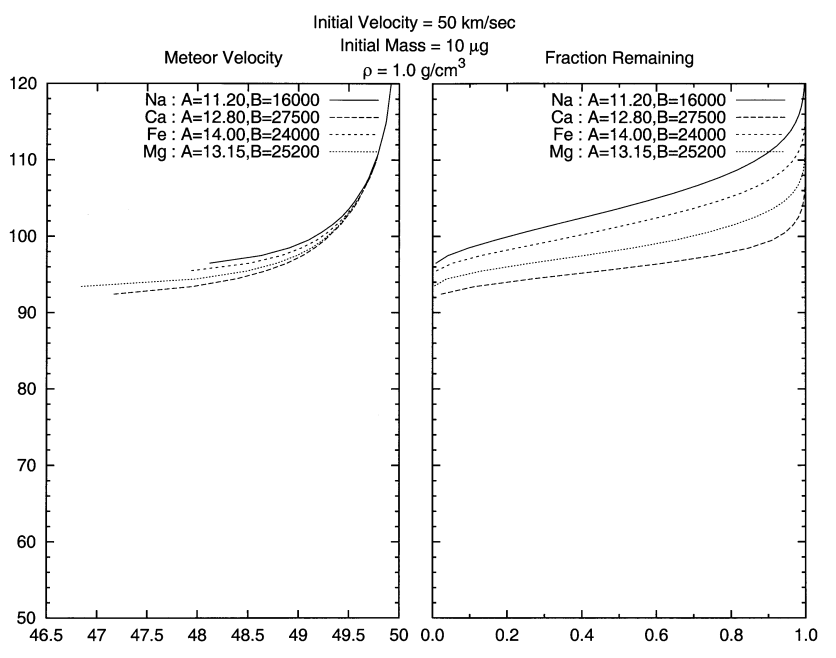

Fig. 5. The ablation of a $10 \mu \mathrm{g}$ particle entering the atmosphere at $50 \mathrm{~km} / \mathrm{s}$.

very high. Na and Fe likely account for most of the ionization seen by the radars. The hyperthermal processes leading to ionization have been discussed in other publications (Dressler and Murad, 2001; McNeil et al., 2001) and may be summarized:

$$
\begin{aligned}
& \mathrm{Na}+\mathrm{O} \rightarrow \mathrm{Na}^{+}+\mathrm{O}^{-} \text {or } \mathrm{Na}^{+}+\mathrm{O}+\mathrm{e} \\
& \mathrm{Fe}+\mathrm{O} \rightarrow \mathrm{Fe}^{+}+\mathrm{O}^{-} \text {or } \mathrm{Fe}^{+}+\mathrm{O}+\mathrm{e}
\end{aligned}
$$

The cross section for reaction (1) is estimated to be $\sim 10^{-15} \mathrm{~cm}^{2}$. There is no estimate for the cross section of reaction (2). However, the reaction of $\mathrm{Fe}$ with $\mathrm{O}_{2}$ to give ionic products (undetermined) is $\sim 10^{-16} \mathrm{~cm}^{2}$ (Bukhteev and Bydin, 1963; Bukhteev et al., 1961; Friichtenicht et al., 1967); the cross section for reaction with $\mathrm{O}$ atoms (i.e. reaction 2) is likely to be greater because of the ready occurrence of resonances in the formation of $\mathrm{Fe}^{+}$and $\mathrm{O}^{-}$. In any case, with $[\mathrm{O}] \sim 10^{12} \mathrm{~cm}^{-3}$, the time constant for reaction of either $\mathrm{Na}$ or $\mathrm{Fe}$ with $\mathrm{O}$ atoms is $\sim 0.1 \mathrm{~ms}$.

The implication of the above discussion is that for 1 and $10 \mu \mathrm{g}$ meteoroids the beginning height would be at $\sim 120 \mathrm{~km}$ and the end height would be at $\sim 90 \mathrm{~km}$, in agreement with the observations (Janches et al., 2000, 2001; Mathews et al., 2001, 1997).

\section{Conclusions}

Perhaps the most important conclusion is that the Arecibo data are explainable in terms of fundamental physical properties of meteoroids. Thus the "necessary" condition is met, but the calculations are not "sufficient" to show that the observations are not biased.
Acknowledgements. The work at Radex, Inc. was supported by the U.S. Air Force contract F19628-98-C-0054. We also thank the reviewer for helpful comments.

Edited by: J. Plane

\section{References}

Alexander, C. M. O. D.: Exploration of the quantitative kinetic models for the evaporation of silicate melts in vacuum and in hydrogen, Meteoritics Planet. Sci., 36, 255-283, 2001.

Bukhteev, A. M. and Bydin, Y. F.: Loss of electrons by fast Ca, Mg, $\mathrm{Si}$ and $\mathrm{Fe}$ atoms in encounters with $\mathrm{N}_{2}$ and $\mathrm{O}_{2}$, Bull. Acad. Sci. USSR, Phys. Ser., 27, 985, 1963.

Bukhteev, A. M., Bydin, Y. F., and Dukel'skii, V. M.: Soviet Phys.Tech. Phys., 6, 496, 1961.

Chase Jr., M. W.: NIST-JANAF Thermochemical Tables, in J. Physical Chemical Ref. Data, American Institute of Physics, Woodbury, NY, 1900, 1998.

Dressler, R. A. and Murad, E.: The gas phase chemical dynamics associated with meteors, in Chemical Dynamics in Extreme Environments, edited by Dressler, R. A., World Scientific, Singapore, 268-348, 2001.

Fegley, J. B. and Cameron, A. G. W.: A vaporization model for iron/silicate fractionation in the Mercury protoplanet, Earth Planet. Sci. Lett., 82, 207-222, 1987.

Flynn, G. J.: Atmospheric entry heating of micrometeorites, in 19th Lunar and Planetary Science Conference, Lunar and Planetary Institute, Houston, TX, 673-682, 1989.

Friichtenicht, J. F., Slattery, J. C., and Hansen, D. O.: Ionization from $\mathrm{Fe}$ atoms incident on various gas targets, Phys. Rev., 163, 1, 75-80, 1967.

Grebowsky, J. and Aikin, A. C.: In situ measurements of meteoric ions, in Meteors in the Earth's Atmosphere, edited by Murad, E. and Williams, I. P., Cambridge University Press, Cambridge, UK, 189-214, 2002.

Hawkes, R. L. and Jones, J.: A quantitative model for the ablation of dustball meteors, Mon. Not. R. Astr. Soc., 173, 339-356, 1975.

Janches, D., Mathews, J. D., Meisel, D. D., and Zhou, Q.: Micrometeor Observations using the Arecibo $430 \mathrm{MHz}$ Radar: I. Determination of the Ballistic Parameters from Measured Doppler Velocity and Deceleration Results, Icarus, 145, 53-63, 2000.

Janches, D., Meisel, D. D., and Mathews, J. D.: Orbital properties of the Arecibo micrometeoroids at Earth interception, Icarus, 150, 206-218, 2001.

Janches, D., Pellinen-Wannberg, A., Wannberg, G., Westman, A., Hägerström, I., and Meisel, D. D.: Tristatic observations of meteors using the $930 \mathrm{MHz}$ EISCAT radar system, J. Geophys. Res., 107, (11A), SIA 14-1-14-14, 2002.

Jones, J. and Kaiser, T. R.: The effects of thermal radiation, conduction and meteoroid heat capacity on meteoric ablation, Mon. Not. R. Astron. Soc., 133, 411-420, 1966.

Love, S. G. and Brownlee, D. E.: Heating and thermal transformation of micrometeoroids entering the Earth's atmosphere, Icarus, 89, 26-43, 1991.

Love, S. G. and Brownlee, D. E.: Peak atmospheric entry temperatures of micrometeorites, Meteoritics, 29, 69-71, 1994.

Mathews, J. D., Janches, D., Meisel, D. D., and Zhou, Q.-H.: The micrometeoroid mass flux into the upper atmosphere: Arecibo 
results and a comparison with prior estimates, Geophys. Res. Lett., 28, 10, 1929-1932, 2001.

Mathews, J. D., Meisel, D. D., Hunter, K. P., Getman, V. S., and Zhou, Q.: Very high resolution studies of micrometeors using the Arecibo $430 \mathrm{MHz}$ radar, Icarus, 126, 157-169, 1997.

McNeil, W. J., Dressler, R. A., and Murad, E.: Impact of a major meteor storm on Earth's ionosphere: A modeling study, J. Geophys. Res., 106, (A6), 10 447-10 465, 2001.

McNeil, W. J., Lai, S. T., and Murad, E.: Differential ablation of cosmic dust and implications for the relative abundances of atmospheric metals, J. Geophys. Res.-D., 103, 10 899-10911, 1998.
McNeil, W. J., Murad, E., and Plane, J. M. C.: Models of meteoric metals in the atmosphere, in Meteors in the Earth's Atmosphere, edited by Murad, E. and Williams, I. P., Cambridge University Press, Cambridge, UK, 265-287, 2002.

Öpik, E. J.: Physics of Meteor Flight in the Atmosphere, Interscience Publishers, New York, 174, 1958.

von Zahn, U., Höffner, J., and McNeil, W. J.: Meteor trails as observed by lidar, in Meteors in the Earth's Atmosphere, edited by Murad, E. and Williams, I. P., Cambridge University Press, Cambridge, UK, 149-187, 2002.

Whipple, F. L.: Meteors and the Earth's upper atmosphere, Rev. Mod. Phys., 15, 246-264, 1943. 